\title{
Quando a formação reflexiva \\ do professor se torna um \\ caso de Supervisão
}

\section{Reflective teacher education developing into Supervision}

\author{
Clícia Bührer MARTINS* \\ Luzia Borsato CAVAGNARI*
}

\begin{abstract}
Resumo: No presente texto objetiva-se apresentar uma análise sobre a correspondência entre tutoria e supervisão escolar e a participação dos tutores na formação reflexiva dos estudantes-professores do Curso Normal Superior com Mídias Interativas - CNSMI da Universidade Estadual de Ponta Grossa/PR, pertencentes ao quarto circuito do curso. A opção por essa temática deu-se pela necessidade de produção teórica na área da supervisão escolar e pela possibilidade do estabelecimento de relações entre o trabalho da tutoria realizado nos cursos de formação à distância e o trabalho da supervisão em âmbito escolar. Além da riqueza do material produzido, o estudo justificou-se ainda pelas inúmeras possibilidades de análise surgidas em função das vivências dos tutores e, especialmente, por tratar-se de um processo singular de formação de professores. A partir do problema e dos objetivos propostos, o trabalho foi desenvolvido por meio de pesquisa bibliográfica e teve como suporte a pesquisa descritivo-interpretativa, realizada por meio da análise documental, dos questionários respondidos pelos tutores e de material constituído pela síntese elaborada de curso produzido pelos estudantes-professores. Do estudo foi possível constatar a existência de consistente formação de tutores e seu acompanhamento pela coordenação pedagógica do CNSMI, o que permitiu o desencadeamento de um processo de formação reflexiva de professores ainda pouco experienciado nos cursos de formação. Apesar dessas condições, o processo reflexivo aconteceu parcialmente e só foi possível nos casos em que os tutores, soman-
\end{abstract}

\footnotetext{
* Mestre em Educação pela UEPG. Professora do Departamento de Métodos e Técnicas da UEPG. Pesquisadora do CEFORTEC-UEPG. Email: mcjm@interponta.com.br

** Mestre em Educação pela UEPG. Professora Aposentada do Departamento de Métodos e Técnicas da UEPG. Pesquisadora do CEFORTEC-UEPG. Email: luziabc@terra.com.br

Olhar de professor, Ponta Grossa, 8(1): 91-105, 2005.
} 
do sua melhor formação anterior aos estudos com a coordenação pedagógica e a disposição em fazer acontecer, também praticaram a reflexão. A ação da tutoria permitiu a consciência por parte dos agentes quanto à necessidade da reflexão sobre a prática profissional e, ainda, da liderança e gestão desse processo na escola pelo trabalho da supervisão.

Palavras-chave: tutoria, supervisão escolar, formação reflexiva de professores

\begin{abstract}
This text aims at presenting an analysis of the relation between tutoring and school supervision and tutor participation in reflexive formation of student-teachers attending the 4th module of the Teacher Training Course with Interactive Medias (Curso Normal Superior com Midias Interativas - CNSMI) of the State University of Ponta Grossa/PR. The reason for choosing this subject was due to the need for theoretical discussions in the field of school supervision and for the possibility of establishing a correlation between the work done in distance tutor-teacher education courses and supervision in a school environment. Another justification for this study is that, as well as producing abundant material, numerous possibilities for analysis arose from the tutors' own experiences and because it was a unique process in the development of teachers. From the moment the issues and aims were proposed, the study evolved based on bibliographic research, more specifically the descriptive-interpretative kind, done through documental analysis of the questionnaires answered by the studentteachers and the analysis of a synthesis of the course organised by the studentteachers. It was therefore possible to verify the existence of a consistent tutor-teacher education and the supervision by the pedagogic coordination of the CNSMI allowing for the beginning of a reflexive process in teachers with little experience in teacher education. In spite of these conditions, the reflexive process was partially successful and was only possible in cases where the tutors possessed better previous formation, knowledge about pedagogic coordination and had the time for enabling this. Tutoring raised awareness for the need of reflection on the teaching practice as well as leadership and management of this process in schools on the part of the supervisors.
\end{abstract}

Key words: tutoring, school supervision, reflective teacher education

As mudanças acontecidas no contexto social, político, econômico, tecnológico e cultural das últimas décadas têm transformado as organizações de modo geral, o mundo do trabalho e, assim, também a maneira como se concebe a educação. Há, pois, nesse cenário, uma pressão por mudanças que vão desde a concepção de escola, sua filosofia e objetivos mais amplos, passam pelos currículos e chegam à sua execução em sala de 
aula - as metodologias, a avaliação da aprendizagem e do processo educacional como um todo. Diante disso, ser professor hoje significa estudar permanentemente, estar aberto às inovações, perceber-se e auto-avaliar-se continuamente, para responder aos desafios postos por um alunado que não aceita mais a simples repetição, a rotina, e por um mercado de trabalho cada vez mais exigente.

Dentre outros, esses são fatores que demonstram a necessidade de formação de professores para a Educação Infantil e os Anos Iniciais do Ensino Fundamental em nível superior, requerido pelo sistema educacional brasileiro especialmente a partir da Lei 9394/96. Muito embora muitos dos cursos de Pedagogia das universidades e instituições de ensino superior brasileiras venham, desde os anos 80 , formando professores para atuar nesse nível de ensino, é com a instituição dos Cursos Normais Superiores que tal modalidade de formação se intensifica.

O Curso Normal Superior com Mídias Interativas (CNSMI), desenvolvido pela Universidade Estadual de Ponta Grossa - UEPG, vem realizando a formação de professores para os anos iniciais do Ensino Fundamental e profissionais em exercício advindos principalmente dos sistemas municipais de ensino de diversos municípios do Estado do Paraná. É importante destacar que a UEPG recebeu certificação do MEC para ministrar cursos de graduação e pós- graduação a distância, dentre eles o CNS, recomendado como referência nacional, credenciado e autorizado pela Portaria do MEC n ${ }^{\circ} 652$, de 16/ 03/04.

O projeto pedagógico desse curso é orientado pela lógica da racionalidade prática em contra-posição à lógica da raciona-lidade técnica, isto é, a que separa a teoria da prática, e entende que "a atividade do profissional é sobretudo instrumental, dirigida para a solução de problemas mediante a aplicação rigorosa de teorias e técnicas científicas" (GÓMEZ, 1995, p. 96).

Uma formação orientada pela lógica da racionalidade prática significa, segundo Yenger (apud GÓMEZ, p. 102) "capacidade para manejar a complexidade e resolver problemas práticos através da integração inteligente e criativa do conhecimento e da técnica". Nessa dimensão, partese da identificação de problemáticas advindas das práticas dos professores nas escolas e da compreensão do modo como utilizam o conhecimento científico para resolver situações incertas e desconhecidas. Assim, na lógica da complexidade, como também é conhecida, "a prática pedagógica está continuamente em construção, uma construção artística e pessoal que a faz ser idiossincrática, características que inviabilizam qualquer tentativa de forjá-la previamente através de modelos preestabelecidos" (NADAL et al, 2003, p. 122).

Para concretizar o projeto peda- 
gógico do CNSMI, a estrutura curricular é composta por módulos interativos, vivências educadoras (a prática no decorrer do curso), estágio, estudos independentes e síntese elaborada de curso (síntese de reflexão entre experiência e formação). Sua operacionalização acontece em ambientes de vídeo-conferência interativa, trabalhos on-line, tutoria permanente e presencial, espaços das escolas e da comunidade. A tutoria e sua participação na formação reflexiva de professores constitui, certamente, o elemento central de todo o processo, o que justifica sua escolha como objeto de estudo e análise deste texto.

Primeiramente, cabe perguntar: qual é o significado da palavra tutor?

Segundo Ferreira (1999, p. 2020), tutor "é o indivíduo legalmente encarregado de tutelar alguém; protetor, defensor; aluno designado como professor de outros alunos, em formas alternativas de ensino".

A segunda parte desse conceito remete à idéia do aluno monitor, figura prevista no método do ensino mútuo baseado em Lancaster e largamente utilizado na história da educação brasileira no século XIX. A relação aluno-aluno se dá, contudo, sob a orientação do professor, cujo papel é assim descrito por Almeida (apud SAVIANI, 1999, p. 22):

Durante as horas de aula para as crianças, o papel do professor limitou-se à supervisão ativa de círculo em círculo, de mesa em mesa, cada círculo e cada mesa tendo à sua frente um monitor, aluno mais avançado, que ficava dirigindo. Fora destas horas, os monitores recebiam, diretamente dos professores uma instrução mais completa, e não era raro ver os mais inteligentes adquirirem a instrução primária superior.

Com essa descrição observa-se que embora não se empregasse a expressão tutoria para fazer referência aos alunos monitores, estes, juntamente com o professor, a exerciam. Cumpriam-se, assim, as normas do Império que, na falta de professores, propunha essa alternativa metodológica. A descrição de Almeida, coloca em relevo o papel do professor no ensino mútuo, que é assim analisado por Saviani (1999): “o professor absorve as funções de docência e também de supervisão. (...) ele instrui os monitores e supervisiona as suas atividades de ensino assim como a aprendizagem do conjunto dos alunos" (op cit, p. 22). É, portanto, no bojo do conceito de tutoria que se insere, além da função docente, também a função supervisora, entendida essa como ação mediadora e estimuladora da conquista da aprendizagem pelos alunos.

O projeto pedagógico do CNSMI (2000) explicita dois papéis para os tutores: o de acompanhamento/diagnóstico e o de certificação das competências. O primeiro centra-se na orientação dos estudantes-professores (e.p.) para a superação de suas dificuldades, principalmente no que tange à mediação entre eles e os docen- 
tes. Em se tratando de um curso de educação à distância que é, ao mesmo tempo, presencial e virtual, os e.p. convivem com docentes tão somente nas videoconferências e nas sessões de assistência e chat. Embora seja uma convivência direta, é mediatizada pela máquina. É com o tutor(a), que também é um profissional professor, que os cursistas têm contato diáriopresencial durante todo o tempo do curso. Assim, o tutor é o professor que acompanha os alunos e participa de todas as suas atividades para estimular a reflexão, propondo aprofundar as temáticas das vídeos e promovendo o confronto teoria-prática. São os tutores que realizam a mediação entre coordenação pedagógica, professores, alunos e conhecimento, em se tratando do desenvolvimento curricular, e que fazem a mediação coordenação geral - coordenação local - alunos, no aspecto administrativo.

Como se observa, os tutores constituem-se em elementos centrais na engrenagem da estrutura do CNSMI, favorecendo o estudo, a discussão permanente das temáticas, oportunizando a inter-relação entre os conteúdos pelas diferentes estratégias e instrumentos adotados no "espaço da tutoria". Por isso, são eles competentes para identificar se estão sendo atingidos os objetivos propostos, pelo acompanhamento e permanente revisão de aspectos não aprendidos pelos e.p. e pela avaliação que resulta na descrição de aspectos qualitativos e quantitativos. Portanto, nessa nova modalidade de formação de professores, o tutor exerce a centralidade do processo e, dependendo das competências técnica, humana e políticaque possui, promove ou deixa de promover em maior ou menor grau o avanço qualitativo da formação docente.

O desenvolvimento das ações no CNSMI pelos tutores ganhou mais importância e visibilidade ao longo dos dois primeiros anos de execução, pela natureza e complexidade do trabalho, fazendo com que a Coordenação Pedagógica viabilizasse processos formativos para "instrumentalizálos com os saberes abordados no curso: aqueles a serem ensinados, bem como os pedagógicos da docência. Ao mesmo tempo, mostra-se fundamental que tutores, instituição formadora e docentes se mantenham próximos, num trabalho articulado por objetivos e linhas de ação comuns" (UEPG, 2003, p.2).

Essa formação tornar-se-á real, na medida em que se possibilite a continuidade da prática reflexiva nas escolas. Para isso, é preciso transformálas em "organizações aprendentes" (ARGYRIS; SCHÖN) ou em "escolas reflexivas", expressão criada por Alarcão (2001), significa "organização que continuamente se pensa a si própria na sua missão social e na sua estrutura, e se confronta com o desenrolar da sua atividade num processo simultaneamente avaliativo e formativo" (op cit, p. 13).

Partindo dessas considerações, entende-se que o trabalho da tutoria 
se identifica com a função conferida pelo cargo que ocupa o supervisor escolar no aspecto da formação continuada do professor em serviço. Nesse sentido, Supervisão Escolar é entendida, neste texto, como a ação mediadora que articula o trabalho da escola e de seus professores por meio da reflexão, da problematização, da análise dos processos de ensino e aprendizagem. É dessa forma que são decididos, com os professores, aspectos essenciais da vida da escola e, na sua especificidade, os processos de aprendizagem. Além da função formadora, a supervisão é centrada na coordenação, isto é, na organização do trabalho pedagógico baseado em princípios comuns definidos no projeto pedagógico (CAVAGNARI, 2003).

No Brasil, a Supervisão Escolar se constitui em forma de cargo/função em muitos sistemas estaduais e municipais de ensino, assumido por educador formado em Pedagogia/Supervisão Escolar. Em outros sistemas escolares, a função é desempenhada por coordenadores pedagógicos: professores não necessariamente graduados em Pedagogia. Já em Portugal, a expressão supervisão começou a ser utilizada nos anos setenta não como designativo de um cargo, mas do exercício das funções dos professores universitários no acompanhamento dos seus alunos em estágio pedagógico nas escolas. E é nesse sentido que Alarcão e Tavares (1987) definem supervisão: "o processo em que um professor, em princípio mais experien- te e mais informado, orienta um outro professor ou candidato a professor no seu desenvolvimento humano e profissional" (op cit, p. 18).

Enquanto no caso brasileiro convive-se com a figura do professor supervisor de estágio, do supervisor em nível de sistema e do supervisor/ coordenador pedagógico que compõe a equipe de gestão educacional em nível de escola, em Portugal pretende-se a ampliação do campo de atuação da supervisão, a fim de, segundo Alarcão (2001,p. 49), “incluir, para além da formação inicial dos professores, também a responsabilidade pelo desenvolvimento qualitativo da escola". Num contexto de escola reflexiva apontada pela autora, o âmbito de atuação redefine-se, assim, como o objetivo da supervisão e se reconceitualiza o supervisor que "fazendo parte do coletivo da instituição e trabalhando em íntima ligação com a sua direção e com os outros níveis de gestão e supervisão, se responsabilize por fomentar ou apoiar o processo reflexivo-formativo da escola" (ALARCÃO, 2000, p. 20).

É preciso considerar, ainda, que a função da supervisão escolar brasileira - criada nos anos setenta com características técnicas visando à eficiência e ao controle da produtividade na escola - assume na atualidade uma dimensão maior na liderança da formação contextualizada e crítica dos educadores. Ao se propor a formação de um professor reflexivo, a supervisão e, nesse caso, a tutoria, as- 
sim têm também que se comportar. Como formar professores que refletem sobre a sua prática, se os próprios formadores não possuem o hábito de pensar sobre o que/por que/como conduzem suas ações?

Em pesquisa realizada com supervisores da rede municipal de ensino de Porto Alegre, Medina (1995) enfatiza a importância da apropriação da prática pelo supervisor e da sua reflexão sobre ela, e afirma que o supervisor abdica de exercer poder e controle sobre o trabalho do professor e assume uma posição de "problematizador" do desempenho docente. A supervisão reflexiva realiza, pois, um duplo movimento: o exercício e a prática de refletir sobre as próprias ações; e o de desencadear, estimular e promover a reflexão sobre o processo de ensino e aprendizagem, com os professores.

Ao pretender a formação de professores reflexivos, a coordenação pedagógica do CNSMI investiu na formação dos tutores. Assim, com a intenção de analisar a correspondência entre tutoria e supervisão, bem como a participação dos tutores na formação reflexiva dos e.p., neste estudo foi utilizada de pesquisa descritivo-interpretativa, tomando por base as respostas dadas a questionário encaminhado para os tutores que atuaram no $4^{\circ}$ circuito (conjunto dos municípios envolvidos: Almirante Tamandaré, Castro, Centenário do Sul, Curitiba, Fazenda Rio Grande, Londrina e Paranavaí).
Dos 24 questionários encaminhados, $63 \%$ foram respondidos pelos tutores, os quais, ao serem questionados sobre a concepção que possuem de tutoria, caracterizaram-na como "peça fundamental durante o curso", reconhecendo na função desempenhada o caráter de "mediador", "incentivador", “instigador", “orientador", “encorajador”. Em sua ação diária, a tutoria representa, de fato, assim como a supervisão em nível de escola, um nível intermediário: Secretaria de Educação-professores ou coordenação geral/coordenação pedagógica-e.p., não somente nas questões administrativas, mas nas didático-pedagógicas e nas relações com a comunidade. Ao considerar a mediação enquanto atributo da tutoria, os tutores a definem como fator de intermediação entre a pedagogia de sala de aula, isto é, tutor-e.p.- e a pedagogia institucional, que diz respeito à relação tutor-coordenação. A relação que se estabelece entre tutor/ supervisor e professores é similar à relação acontecida em sala de aula entre professores e alunos.

Ao exercer o papel de mediadores, tanto tutores quanto supervisores não assumem a tarefa dos estudantes professores ou dos docentes, pensando e agindo por e para eles. Cabelhes instigar estudantes e docentes e incentivá-los, questionando-os, provocando-os a pensar, a refletir, a descobrir, a encontrar respostas aos problemas da teoria e da prática em sala de aula. Nesse aspecto, a tutoria e a 
supervisão contribuem na formação do professor na passagem, segundo Saviani, do "senso comum à consciência filosófica". E isto é mediação. Ao realizar a mediação, a tutoria/supervisão é quem possui a visão do todo ou, como afirma uma das tutoras: "a visão global do curso, pois torna-se uma professora multidisciplinar com certos limites, é claro!" Portanto, a função tutor/supervisor não se identifica com a do profissional "especialista", que exerce ações fragmentadas, mas que facilita a interrelação das partes, isto é, das disciplinas/áreas do conhecimento, administração central/escolas.

A partir da definição do papel do tutor/supervisor enquanto mediador, isto é, aquele que facilita o avanço da relação que se estabelece entre o aluno e o professor (VASCONCELLOS, 2002), cabe retomar a discussão a respeito da possibilidade de esses profissionais estarem contribuindo para a formação reflexiva dos e.p. A ação do tutor/supervisor situa-se na interação entre o pensamento e a ação, com o objetivo de dar sentido ao vivido e ao conhecido, ou seja, de compreender melhor para melhor agir (ALARCÃO, 2003). Não tem ele a pretensão de resolver as situações-problema que se apresentam aos e.p., e sim, coletivamente, procurar respostas que se originem do consenso entre os mesmos. Nesse sentido, o papel do tutor/supervisor estende-se à noção de facilitador no processo de mediação dialética entre teoria e prá- tica, fazendo com que os professores, em grupos de trabalho, ajam de forma reflexiva, indagadora e explicitem as suas teorias práticas. Para tanto, muito contribuem as estratégias de formação de professores, amplamente utilizadas em países como os Estados Unidos e Portugal, como um meio de formar professores reflexivos, uma vez que elas envolvem processos de reflexão, tanto por parte do supervisor, como do professor em formação. Embora venham sendo aplicadas no contexto da formação inicial, Alarcão, Amaral, Moreira e Ribeiro sinalizam para a possibilidade de se trabalhar com tais estratégias de formação de professores reflexivos no âmbito da formação continuada em serviço.

Essas estratégias são utilizadas como instrumentos de apoio à reflexão, compreendida como o movimento de repensar sistematicamente a ação para torná-la mais coerente, mais lúcida, assim como para melhorá-la e aprofundar o conhecimento sobre ela. Dentre as estratégias propostas pelos autores anteriormente citados, selecionamos as "perguntas pedagógicas" e a "observação de aulas" (AMARAL; MOREIRA; RIBEIRO, 1996). Tal opção se justifica em função das características diferenciadas e muito peculiares da relação tutore.p. do CNSMI, sujeitos da pesquisa.

Nas perguntas pedagógicas, o supervisor questiona o professor em relação à validade ética de certas práticas e crenças demonstradas por ele, 
como meio de restituir-lhe o seu papel de intelectual. Dessa forma, as perguntas devem estar direcionadas de tal forma que procurem desvendar as forças sociais, culturais e políticas que têm direcionado a prática do professor e que impedem que estes mudem as suas convicções mais enraizadas.

Para adquirirem significado, as perguntas, bem como as demais estratégias de formação, devem centrarse em torno de situações-problema vividas pelos professores em formação no seu próprio contexto de trabalho. Alarcão (2003) refere-se ao diálogo formativo entre professor e supervisor, alicerçado na observação e na capacidade de escuta atenta deste às colocações/angústias/necessidades daquele. As perguntas direcionadas ao professor não são totalmente abertas, uma vez que demonstram a necessidade de caracterizar o problema através da identificação de fatores. Ao questionar, o supervisor procura direcionar e desencadear o processo reflexivo por meio de perguntas como: qual terá sido a causa de tal situação? Foi possível identificar os fatores? Entretanto, pode-se observar que a pergunta mantém-se aberta à reflexão, com base na observação do professor.

Com a finalidade de dar seqüência a esse processo reflexivo, juntamente com os estudantes professores, o tutor/ supervisor pode estar retomando conceitos já estudados com o grupo nos momentos de formação.
Em função dos relatos dos professores sobre as situações-problema que emergem da prática, como, por exemplo, a indisciplina dos alunos em sala de aula, o supervisor pode estar questionando-os a respeito de que ponto de vista teórico tal situação de indisciplina pode ser analisada. Como é que a Psicologia, a Sociologia, a Didática podem estar justificando tal comportamento do aluno (relatado pelo professor)?

A partir dos relatos dos estudantes professores, o tutor/supervisor pode estar levantando categorias e analisando-as, juntamente com os professores, frente a um quadro conceitual organizador da ação.No caso do CNSMI, esse quadro referese a toda a teoria presente no curso, à qual os e.p. têm acesso através das videoconferências e dos textos estudados, principalmente. Em se tratando de professores em processo de formação continuada nas escolas, o quadro conceitual diz respeito aos estudos teóricos realizados com eles em grupos de estudo, cursos, dentre outros eventos.

No desenvolvimento da presente pesquisa, quando questionados a respeito de como encaminhavam as discussões com os estudantes-professores - de modo a conseguir que estabelecessem a relação entre a teoria aprendida ao longo do curso e os relatos das vivências/estágios realizados, assumindo uma posição crítica quanto à sua prática profissional muitos tutores do CNSMI mostraram, 
em suas respostas, que a concepção de formação reflexiva que predomina entre eles é diferente daquela que entende essa formação como trabalho de reflexão crítica sobre as práticas e de (re)construção permanente de uma identidade pessoal, por parte do professor. É o que se pode depreender do depoimento a seguir.

"Procurava realizar muitas atividades de motivação e troca de experiências entre os estudantes, análise da prática de cada um, sempre relacionando a teoria à prática, muito estudo de texto, dinâmica de grupos, seminários e debates em sala de aula" (Tutora B).

Nesse caso específico, a concepção de formação reflexiva parece estar relacionada à mera acumulação de teorias, uma vez que a tutora não faz nenhuma referência à forma como conduzia o processo de "análise da prática" dos e.p. "sempre relacionando a teoria à prática". Na sua fala, aparece uma relação muito próxima entre "análise da prática de cada um" e "muito estudo de texto". No entanto, em relação à mesma questão, alguns tutores demonstraram uma concepção diferenciada quanto à efetivação da formação reflexiva do estudante-professor:

"Uma das estratégias que eu utilizava era a socialização das dificuldades no grupo de tutoria, seguindo-se de exemplos da minha prática e da reflexão grupal sobre o que realmente estaria in- terferindo no processo. Levei muitos livros de apoio. Houve muitos momentos nos quais o grupo reconhecia as falhas do processo ensino-aprendizagem e se dispunha a discutir, questionar e rever suas ações em sala de aula (Tutora F).

"No CNSMI, o que mais se enfatizou foi a reflexão sobre a própria prática à luz da teoria discutida nas videos. Buscou-se despertar nos e.p. um processo de retomada daquilo que já fazem, procurou-se reavaliar cada momento, cada prática, procurando estabelecer relações com o que os teóricos nos dizem e como que nos deparamos no dia a dia da sala de aula. Como o tutor está cotidianamente ao lado dos alunos e é um profissional do ensino com um tempo maior de vivência, tende a estabelecer um elo de discussão constante, pois, pelo conhecimento da prática do professor, resgata ações para amplo debate reflexivo, pondo em xeque algumas de nossas práticas realizadas empiricamente. As vivências e o estágio, sendo uma exigência do curso, possibilitaram que esse processo se ampliasse, pois, "obriga-se" a refletir sobre o que se faz, por que se faz, para quem se faz, e, principalmente, como se faz e com que qualidade. As discussões sempre eram precedidas de estudos sobre os temas abordados nas 
videos. Sempre procurou-se dar prioridade aos relatos de experiência para se "engatar" uma boa discussão. Quando o professor fala da própria prática, fica mais fácil iniciar o estabelecimento de relações com a teoria" (Tutora D).

Das afirmações das tutoras F e D pode-se observar que houve uma produção gerada no seio da relação entre tutor-estudante professor e que poderia ser entre supervisor-professor em formação, o que Alarcão (2003, p. 72) denomina de "construção situada do conhecimento", uma vez que "os conceitos, na sua grande maioria , têm um lado funcional”. É possível perceber a clara intenção dos tutores de estabelecer a ligação entre ação e cognição, prática e teoria.

A observação de aulas do professor em formação permite ao tutor/ supervisor o reconhecimento das situações que surgem em sala de aula e que poderão, posteriormente, serem analisadas/refletidas juntamente com os e.p. Para que essa observação contribua para a prática reflexiva do professor, torna-se importante que o tutor/supervisor tenha estabelecido acordos prévios com o estudantesprofessores e, ao mesmo tempo, delimitado critérios para essa observação que tenham significado para eles. $\mathrm{O}$ objetivo da observação de aulas é rever com o professor seus procedimentos, analisar se as respostas dadas aos alunos foram adequadas e pensar como intervir de maneira mais efi- ciente para que o aluno aprenda. Essa estratégia de formação de professores torna-se especialmente importante quando se constata que, em certas situações, os professores não se dão conta de que existe um descompasso entre o que pensam e o que fazem, pois atuam segundo teorias diferentes daquelas que professam (CLEMENTI, 2001).

Quando indagadas a respeito das dificuldades encontradas no encaminhamento das discussões com as estudantes professoras, de modo a conseguir que estabelecessem relação entre a teoria aprendida ao longo do curso e os relatos das vivências/estágios realizados, uma tutora assim se pronunciou:

"Teoricamente as estudantes professoras são ótimas, o dificil é fazê-las perceber que a sua prática não está no mesmo nível" (Tutora E).

"Alguns alunos não percebem suas dificuldades, necessitando de auxílio e muita atenção para que possam descobrir-se e avançar" (Tutora G).

É na dicotomia entre o pensamento e a prática do professor que grandes descobertas podem ocorrer, uma vez que, segundo Clementi (2001, p. 58), "ao professor, é permitido admirar-se, indagar, não saber responder, ter de procurar. É papel do coordenador organizar momentos para que isso aconteça". Ainda em relação às dificuldades encontradas, as respostas 
da maioria das tutoras giraram em torno da questão da resistência dos e.p. ao processo de reflexão sobre a sua própria prática pedagógica. Para elas:

“A posição crítica em relação à sua própria prática veio apenas para algumas. Nem todas conseguiram perceber que poderiam ser melhores, pois já se achavam ótimas, infelizmente. Poderia dizer que para levá-los à condição de professores reflexivos e criticos da sua própria prática muito tive que 'salivar', ou seja, todo e qualquer momento era momento de discussão, debate, de tomada de posição, de troca de experiências." (Tutora D)

"É dificil aceitar os vícios que adquirimos no decorrer de nossa caminhada como educador. As e.p. resistiam às mudanças propostas" (Tutora I).

"As pessoas acostumam a agir sempre da mesma forma e quando aparecem mudanças elas relutam e não querem aceitar" (Tutora J).

Tais resistências das estudantes professoras certamente estão relacionadas ao que Dewey (1968) define como atitudes básicas ao processo reflexivo. São elas: a abertura de espírito para a reflexão, que envolve a capacidade de admitir a possibilidade do erro, mesmo naquilo que se acredita como certo; a responsabilidade sobre as conseqüências pessoais, sociais e políticas dos efeitos da sua ação so- bre os alunos; e a disposição para enfrentar a atividade com energia e curiosidade, lutando contra a rotina.

A observação de aulas, assim como as perguntas pedagógicas, têm por objetivo o desenvolvimento profissional do professor, pela possibilidade de ele adquirir maior consciência e, portanto, mais controle sobre a forma como conduz sua própria prática pedagógica, pela compreensão do que faz, do que vê fazer e do que se passa em sala de aula.

Um dos momentos privilegiados na formação do professor reflexivo tem se constituído pela síntese elaborada de curso (s.e.c.), que consiste na sistematização gradativa do conhecimento acumulado e do saber apropriado nos diversos momentos (memorial, saberes específicos e pedagógicos, das vivências e estágios) a partir da reflexão e produção pessoal, inspirada na construção coletiva do conhecimento, analisada e comentada em função de diferentes aspectos de sua prática. Esse processo conjuga narrativas e perguntas pedagógicas num movimento contínuo de descrição e análise crítica dos saberes e práticas realizadas pelos estudantes professores antes da entrada no CNSMI, com as ações e saberes apreendidos e vivenciados no decorrer do curso e a possível superação das problemáticas ainda presentes no cotidiano escolar.

A participação dos tutores, ao orientarem os estudantes professores na s.e.c., foi considerado como "o momento principal do curso” (Tutora 
B); "o momento de reflexão mais profunda" (Tutora P); e, conforme a tutora $\mathrm{C}$, "como uma possibilidade muito grande de reflexão, pois ela busca no baú as coisas do passado, trazendo-as para o presente para, com certeza, melhorar seu futuro nos pontos que precisam ser modificados. Isso se pode perceber bem, pois é árduo o acompanhamento individual que se faz com cada uma delas: discute-se, reflete-se, indaga-se muito para que possam realmente repensar sua prática em relação à sua conduta profissional e também em relação ao trabalho com as áreas do conhecimento".

O exame das falas das tutoras indica a relevância que a s.e.c. teve para elas, o que significa também o compromisso e seriedade da Coordenação Pedagógica do CNSMI, ao propor um trabalho que ultrapassasse a simples descrição ou relato, ou que favorecesse a cópia. Há, na afirmação da tutora, o esforço por ela empreendido na formação voltada para a lógica da racionalidade prática prevista no projeto pedagógico do curso, pois "não se trata mais de estudar uma teoria a ser futuramente aplicada, mas de, a partir do conhecimento e consciência das condições de atuação na escola, promover a necessária articulação teoria-prática" (GIOVANNI, 2003, p. 216).

Para a maior parte das tutoras, o processo reflexivo evidenciou-se na s.e.c. em maior grau por alguns estudantes professores e em menor grau por outros. Muitas delas perceberam a necessidade de mudanças e, para tanto, " a reflexão foi o ponto de partida” (tutora J). Embora exista ainda uma grande preocupação com a apresentação do trabalho enquanto instrumento de avaliação, documento a ser entregue ou etapa a ser vencida no CNSMI, alguns grupos demonstraram a possibilidade de romper com essa prática, justificada pela maneira como a tutora encaminhava as reflexões. Nesse aspecto, as perguntas pedagógicas utilizadas como referência no trabalho da tutoria na s.e.c., significaram para as tutoras um grande desafio, um trabalho "árduo", exigindo muita leitura e estudo para "provocar as discussões entre o grupo”, como argumenta a tutora D. Daí se depreende que a sistemática de formação reflexiva desenvolvida possibilitou aprendizagens, desconstrução e construção de novos conhecimentos, tanto por parte das tutoras, que também vivenciaram etapas da elaboração da síntese, quanto pelos estudantes-professores.

Um exame das sínteses construídas e a observação das apresentações permitem concluir que os cursistas valorizaram sobremaneira a atuação das tutoras, que humanizaram as relações no curso, estimularam as reflexões, favoreceram os objetivos previstos. Afirmações de e.p. resumem a importância da tutoria e sua correspondência com a Supervisão, quando declararam a algumas das tutoras nos momentos de observação de au- 
las e nas discussões no espaço da tutoria: "Era isto que as supervisoras deveriam fazer nas escolas!". Se não houve um processo reflexivo em toda a sua plenitude, a formação recebida permitiu a consciência de tal necessidade e da liderança e gestão desse processo na escola, sob a forma da Supervisão.

\section{REFERÊNCIAS}

ALARCÃO, I. Escola reflexiva e supervisão: uma escola em desenvolvimento e aprendizagem. In: (Org.). Escola reflexiva e supervisão. Porto: Porto Editora, 2000.

ALARCÃO, I.; TAVARES, J. Supervisão da prática pedagógica: uma perspectiva de desenvolvimento e aprendizagem. Coimbra: Almedina, 1987.

. Do olhar supervisivo ao olhar sobre a supervisão. In: RANGEL, M. (Org.). Supervisão pedagógica: princípios e práticas. Campinas: Papirus, 2001.

Professores reflexivos em uma escola reflexiva. São Paulo: Cortez, 2003.

AMARAL, M. J.; MOREIRA, M. A.; RIBEIRO, D. O papel do supervisor no desenvolvimento do professor reflexivo. In: ALARCÃO, I. (Org.). Formação reflexiva de professores: estratégias de supervisão. Porto: Porto Editora, 1996.

CAVAGnARI, L. B. Áreas de abrangência e atuação da supervisão escolar. Ponta Grossa, 2003. (mimeo)

CLEMENTI, N. A voz dos outros e a nossa voz: alguns fatores que intervêm na atuação do coordenador. In: ALMEIDA,
L. R.; PLACCO, V. M. N. S. (Orgs.). O coordenador pedagógico e o espaço da mudança. São Paulo: Loyola, 2001.

DEWEY, J. Expérience et éducation. Paris: A.Colin, 1968.

FERREIRA, A. B. Novo Aurélio século XXI: o dicionário da língua portuguesa. 3. ed. Rio de Janeiro: Nova Fronteira, 1999.

GIOVANNI, L. M. O ambiente escolar e as ações de formação continuada. In: TIBALLI, E. F. A.; CHAVES, S. M. (Orgs.). Concepções e práticas em formação de professores: diferentes olhares. Rio de Janeiro: DP\&A, 2003.

GÓMEZ, A. P. O pensamento prático do professor: a formação do professor como profissional reflexivo. In: NÓVOA, A. Os professores e a sua formação. Lisboa: Dom Quixote, 1995.

MEDINA, A. S. Supervisor escolar: parceiro político-pedagógico do professor. In: SILVA JR, C. A.; RANGEL, M. (Orgs.). Nove olhares sobre a supervisão. Campinas: Papirus, 1997.

NADAL, B. G.; CAVAGNARI, L. B.; SANTOS, S. A síntese elaborada de curso como metodologia reflexiva de formação: a experiência do Curso Normal Superior com Mídias Interativas. Olhar de professor, Ponta Grossa, v. 6, n. 1, p. 119-134, 2003.

PROJETO de formação continuada para tutores do Curso Normal Superior com Mídias Interativas. Ponta Grossa: UEPG, 2003.

PROJETO pedagógico do Curso Normal Superior com Mídias Interativas UEPG/ UEB - Programa Especial de Formação de Professores em Exercício: licenciatura das séries iniciais e do ensino fundamental. Ponta Grossa: UEPG, 2000. 
SAVIANI, D. A supervisão educacional em perspectiva histórica: da função à profissão pela mediação da idéia. In: FERREIRA, N. S. C. (Org.). Supervisão educacional para uma escola de qualidade. São Paulo: Cortez, 1999.

VASCONCELLOS, C. S. Coordenação do trabalho pedagógico: do projeto político-pedagógico ao cotidiano da sala de aula. São Paulo: Libertad, 2002.

Encaminhado em 14/03/05

Aceito em 12/05/05 